Security Dialogue 2015, Vol. 46(1) 86- 105 DOI: 10.1177/0967010614557884

Constructing resilience through security and surveillance: The politics, practices and tensions of security-driven resilience

Jon Coaffee

University of Warwick, UK

Pete Fussey

University of Essex, UK 


\begin{abstract}
This article illuminates how, since $9 / 11$, security policy has gradually become more central to a range of resilience discourses and practices. As this process draws a wider range of security infrastructures, organizations and approaches into the enactment of resilience, security practices are enabled through more palatable and legitimizing discourses of resilience. This article charts the emergence and proliferation of security-driven resilience logics, deployed at different spatial scales, which exist in tension with each other. We exemplify such tensions in practice through a detailed case study from Birmingham, UK: 'Project Champion' an attempt to install over 200 high-resolution surveillance cameras, often invisibly, around neighbourhoods with a predominantly Muslim population. Here, practices of security-driven resilience came into conflict with other policy priorities focused upon community-centred social cohesion, posing a series of questions about social control, surveillance and the ability of national agencies to construct community resilience in local areas amidst state attempts to label the same spaces as 'dangerous'. It is argued that security-driven logics of resilience generate conflicts in how resilience is operationalized, and produce and reproduce new hierarchical arrangements which, in turn, may work to subvert some of the founding aspirations and principles of resilience logic itself.
\end{abstract}

Keywords: human security, resilience, security, surveillance, terror 


\section{Constructing resilience through security and surveillance: The politics, practices and tensions of security-driven resilience}

\section{Introduction}

Since the early 2000s, the so-called 'resilience turn' (Coaffee, 2013) has seen ideas, discourses and logics of resilience embedded in an array of social and urban policy and practice at a range of spatial scales, driven by an overarching requirement to secure the future from disruptive challenges, threats and events (Coaffee, 2010; Walker and Cooper, 2011). The rhetoric of resilience has now permeated a range of disparate disciplinary areas, a diversity of policy narratives, worlds of professional practice and the popular media. The resilience literature has focused on, for example, cli- mate change adaption, disaster risk recovery, economic recovery, migratory trends, individual and group psychology, child education or, more broadly, a general sense of uncertainty about the future (see, for example, Luthar et al., 2000; Masten, 2001; Raco and Street, 2012). However, this article argues that these diverse meanings and practices of security have become the most potent driver and shaper of contemporary resilience practices. In turn, these have served to generate multiple competing 'logics of resilience' identified and explored in this article. Conversely, this article pro- poses the concept of 'security-driven resilience' to capture multidirectional processes in which resilience policy becomes increasingly driven by security concerns and, at the same time, security policy adopts the language of resilience. As this article will demonstrate, such processes present a range of implications, including the narrowing of formerly diverse resilience concerns towards very specific forms of security and, at the same time, generating multiple governmental, scaling and coercive implications.

This article is situated within the anticipatory turn in social control practices (Fussey, 2013) and at the intersection of concepts of security and resilience. Particular emphasis is also placed on how collapsing distinctions between internal and external security draws multiple new actors and agencies into the delivery of security-driven resilience. To conceptualize and chart the emergence of what we term security-driven resilience we have referred to a range of emergent literatures from surveillance studies; the revolution in military affairs; human security; and state-rescaling and emerging narratives of new localism and resilient citizenship. In turn, these have collectively sought to pull security away from its traditional bias and to focus upon the everyday needs of people and population (Coaffee and MurakamiWood, 2006; Chandler, 2012). Using this conceptual framing, this article is developed with regard to two main areas of analysis.

First, we highlight resilience as an evolving and ongoing process and chart the emergence and embedding of new security logics within resilience policy and practice at multiple scales: on one hand, developing an array of national policy guidance and strategies; while, on the 
other, ostensibly decentralizing power and responsibility to the local scale, inverting traditional security logics based on state level control. Such devolutionary processes generate questions about the localization of security-driven resilience practice, the importation of existing scales to the local level and the generation of new hierarchies within emergent networks of practice. Here, the practices and application of public surveillance programmes are characterized as an exemplification of the weighting of resilience practices towards security concerns, yet are seen to perform a range of more benign functions. In doing so, the second part of the article explores how tensions brought about through such rescaling and reconceptualization of security-led resilience are embodied in practice, by means of a detailed case study example from Birmingham, UK. This case study focuses upon 'Project Champion' - an attempt by the police to install over 200 high-resolution surveillance cameras, often invisibly, into areas with predominantly Muslim populations, ostensibly to deliver a range of security and resilience benefits including protection from crime, radicalization and inter- national terrorism. This case study captures how the practices of state-driven security and resilience are drawn into conflict with other policy priorities relating specifically to community cohesion and localism. It also captures a process by which military technologies have been increasingly utilized in civic spaces, posing a series of questions about social control, citizenship and the ability to construct community resilience in local areas amidst state attempts to label the same areas as 'dangerous'. We conclude by reflecting upon how new logics, hierarchies and practices of security-driven resilience generate a range of tensions and antagonisms which, in turn, produce a number of material and political consequences which serve to fragment further coalitions of resilience practice and may ultimately subvert some of the founding principles of resilience. The article thus examines the complex interplays between three main themes: resilience, security and surveillance. The central argument rests on how proliferating resilience practices are increasingly weighted towards security concerns and that public surveillance operations may be seen as an exemplar and reveal a range of corollaries, consequences and tensions of this shift. In particular, the article focuses on how the deployment of public surveillance initiatives, as part of the broader process of security-driven resilience, both narrows their application towards very specific coercive forms whilst simultaneously commuting more broadly conceived resilience practice towards tightly specified security-focused goals. Before exploring these interrelationships and logics in more detail, the article first explores the meaning and evolution of the key operational concepts of resilience, security and surveillance.

\section{The 'resilience turn', scales of security and the practice of surveillance}

In recent years the emergence, evolution and growth of resilience discourse and practice has become well documented (see, for example, Chandler 2014) and does not necessarily benefit from a detailed rehearsal here. The concept of resilience incorporates a vast range of contemporary risks and security challenges (UNISDR, 2012; Walker and Broderick, 2006; Zolli and Healy, 2012) and, after 9/11, has increasingly become a central organizing metaphor

within the expanding multi- scalar institutional framework of national security and 
emergency preparedness (Adey and Anderson, 2012; Joseph, 2013).

Over time, the lexicon of resilience has grown in international prominence with a focus on resilience practices seen as simultaneously proactive and reactive, with in-built adaptability to the fluid nature of myriad threats and hazards challenging states and their territories. Resilience has thus been applied to the capacity to resist, absorb, recover from and adapt to a range of perturbations. Thus, the spread of resilience discourse (see, for example, Coaffee, 2009) has intimated the simultaneous response to 'all hazards' in which numerous threats and hazards, both "natural" and human induced, are drawn together' (Dainty and Bosher, 2008).

However, the growing canon of critical resilience scholarship has generated a number of core debates that serve as critical contexts for this present article. First among these concerns is the futility of searching for a homogenous definition of resilience. For all the recourse to resilience ur-texts - such as the work of Holling $(1973 ;$ 2001) - or conceptual staples such as subsidiarity, redundancy and adaptability, the growing acknowledgement that ideological, institutional, cultural, social and normative considerations shape how resilience is mobilized in different organizational, social and spatial settings is particularly noteworthy. It could instead be contended that focus is better placed on how resilience is enacted, and what its performative roles and implications are. Thus, what resilience is becomes less important than what it does. Increasingly common within this approach is to see resilience in relation to varied forms of neoliberal governance (O'Malley, 2010), such as its role in fomenting decentralizing forms of governance (Amin, 2013) or championing of utilitarian neoliberal citizenship (Neocleous, 2013: 5). A corollary of this concerns the manifold and localized ways in which resilience becomes interpreted and translated into practice. Here, further relevant debate concerns the extent to which resilience practice represents transformative or radical change, comprises a superficial rebranding of existing practices (such as risk management) or operates in the service of enduring processes such as localization, responsibilization or neoliberalization.

Parallel discourses and practices of security have also followed a number of neoliberalizing, diversifying and decentralizing tendencies. For example, security policy in the orthodox view regularly embodied a spatial focus on a national or supra-national scale (Booth, 2004). Since the 1990s, however, emerging ideas of 'human security' have increasingly come to prominence and attempted to pull security away from its institutional bias, and focus it on the needs of people and populations and, in so doing, remap scale in security. This work coincided with a progressive reassertion of the importance of scale in political geography and the deployment of the 'politics-of- scale' metaphor (see, for example, Brenner, 2000) to illuminate the ways in which politics explicitly constrains scale choices and 'to theorise the scalarity of sociospatial life' (Fraser, 2010). Here, there has been a shift from traditional Euclidian, Cartesian and Westphalian notions of scale and territory as a fixed stable bounded container to notions of scalar practices where governance and institutional frameworks are 
utilized largely, but not exclusively, by the state, to gain competitive advantage and to engage in new networked relations through rescaling (Fraser, 2010: 332).

Although driven by developments such as globalization and devolution, the politics of scale has strong resonance with the emerging and fluid geo-political landscape of security. For example, responses to a range of international terrorist attacks, since 9/11 in particular, have increasingly highlighted the importance of sub-national and localized responses to new security challenges, which require analysis through a different frame of reference than that of the realist state-centric security studies orthodoxy, 'placing the needs of the individual, not states, at the centre of security discourses' (Chandler, 2012: 214). As has been argued, 'security is becoming more civic, urban, domestic and personal: security is coming home' (Coaffee and Murakami-Wood, 2006: 504).

Overall, discourses and practices of resilience and of security have developed in parallel and heavily imbricated ways. For example, we can chart how the ideas underpinning the political rhetoric of resilience have also become more civic-centred and reapplied across a spectrum of multi-scalar socio-economic systems (Burby et al., 2000; Coaffee et al., 2008), similar to ideas of security outlined above. The picture is complicated further by the way that a broader discursive shift in policy - from security to resilience - has subsequently been used to frame associated practices in the post-9/11 world. This is as a consequence of the altered geopolitical relationship between the nation state and security - essentially constructing a deterritorialized view of risk - which attempts to soften the vocabulary of 'emergencies' and focus upon a more positive terminology - resilience - rather than that of threat, vulnerability, disaster management and security (Coaffee, 2006; 2013). Yet, for all the seeming benignity and diversification of focus implied in resilience discourse, we argue that notions of resilience have increasingly adopted and come to resemble security concerns, thus constituting the growth of security-driven resilience. Not only does this signify a narrowing of the polymorphic range of concerns implied by resilience towards those of security and, particularly, counter-terrorism, but it also generates a range of governmental, scaling and coercive implications.

The third operational concept, surveillance, has been a continual feature of human societies stretching back to antiquity, embedded into ancient architectural forms and, later, exercised through the collection of census data for taxation and conscription. Modernity saw important changes in the use of surveillance, because it enabled multiple ordering and organizing processes, and operated as a means to make visible a series of variously imagined forms of urban dangerousness including disease, dissent and destitution. Surveillance practices thus diversified and extended beyond mere observations to become a means to make cities legible (Fussey and Coaffee, 2012). As the city developed it became host to a range of increasingly intensified surveillance practices that worked to coerce, regulate and order elements of urban life. The 20th century brought rapid changes in the ubiquity, potency and technological sophistication of surveillance practices and, as the century turned, 9/11 further 
catalyzed these developments and shepherded in many new coercive and auto- mated analytical applications. Most recently, attention has turned to the enormous data harvesting operations of UK and US intelligence agencies sanctioned by licentiously interpreted 9/11related legislative enablers such as s215 of the Patriot Act (Greenwald, 2014).

Despite the 'serious and immediate consequences' (Bauman et al., 2014: 122) of the revelations in 2013 by Edward Snowden, it is important to recall the considerable diversity, application and purpose of surveillance practices. Surveillance is 'Janus faced' (Lyon, 1994), implicated in care as well as coercion, inhabits many forms and performs myriad functions. In such contexts, and despite its scale and significance, NSA dataveillance should not be considered as a synecdoche for surveillance practices more generally or for all security forms more specifically. This article focuses on the role of one particular form, public space surveillance, as a tool of risk and security practice that has become deployed under the wider and more palatable aegis of resilience. In doing so, we argue that it both narrows the possibilities of surveillance applications towards the coercive and draws resilience practice towards more tightly specified security-focused goals.

\section{UK resilience and security discourse: From hybridity to colonization?}

Relationships between the imbricated realms of security and resilience are complex and multidirectional. In particular, security concerns have gained prominence within a range of articulations of resilience practice. At the same time, security practice has been increasingly repackaged in more palatable expressions of resilience. Prior to 2000 resilience was a term seldom heard in security policy circles. Whereas securing state assets against international terrorism had long been a government priority, this was an agenda that had been almost exclusively delivered by state security services. In 2000 and early 2001 a series of disruptive events in the UK - strategically targeted nationwide protests on the transport network; the foot and mouth disease outbreak; a number of inland flooding episodes - highlighted several organizational failings which served to emphasize that reform of national emergency planning procedures was long overdue. The subsequent events of $9 / 11$, and the concern that key UK sites would be targeted by terrorists, accelerated this process and made reform of emergency preparedness a political priority. National security policy was thus increasingly focused on the need to respond proactively and develop pre-emptive solutions to per-ceived security threats. For all the emphasis on anticipation, and the language of preparedness, anticipation and risk it was at this juncture that the term 'resilience' came to the fore (Coaffee, 2006) and was eventually formalized in policies and practices following the 2004 Civil Contingencies Act (CCA); for example, the associated National Resilience Capabilities Programme and subsequent creation of multi-agency Local Resilience Forums. ${ }^{1}$ Following the introduction of the CCA, the UK government attempted to provide a central strategic direction for developing resilience, based on a cycle of anticipation, prevention, preparation, response and recovery (Cabinet Office, 2005). Subsequent national security and counterterrorism policies - notably the overarching Countering International Terrorism Strategy 
(CONTEST) (HM Government, 2006), the UK's first national security strategy (Security in an Interdependent World [Cabinet Office, 2008]) and the initial anti-radicalization approach (Preventing Violent Extremism [HM Government, 2008]) -interlinked in various ways with the provisions of the CCA to form a powerful top-down state- driven logic for 'resilience' policy. 2,3,4 Individually and collectively these policy narratives signified an increasingly complex and fluid landscape where multiple threats were being faced and which required coordinated responses across a range of scales and stakeholder groups, including local communities. As these responses have evolved, a number of different security-driven resilience logics, each encompassing complex relationships between security and resilience, can be identified. Here, resilience policy becomes increasingly mobilized by security concerns and, at the same time, security policy adopts the language of resilience. Moreover, as these logics develop and unroll through a range of practices, a series of incompatibilities and tensions within and between different thematic and scalar approaches can be seen to emerge.

The UK has perhaps gone furthest in developing security-driven resilience policy since 9/11. This article charts the surfacing and progression of different 'logics' of resilience over the last decade with a focus on UK politics and policy making at a range of scales. Changing practices of resilience have emerged as both a function of time and in relation to a range of changing socio- political and economic pressures which have shaped an evolving meaning and operational function of resilience. In particular, we emphasize the prominence of security concerns within such articulations of resilience discourse which, as a corollary, have drawn a number of security practices and infrastructures, such as surveillance, into the delivery of resilience practice. For example, and as we will highlight, the logics underpinning UK resilience policy have responded to the changing targeting preferences of international terrorists (Coaffee, 2010) concerns over 'radicalization' (Briggs, 2010) as well as a renewed interest in localism as a means of building enhanced community resilience (Cabinet Office, 2011a). As the discussion below relates, surveillance practices have been implicated in the delivery of each of these. We pay particular attention here to the tensions that have emerged as a result of the simultaneous adoption of security-driven resilience practice at a range of spatial and governance scales.

\section{Security-driven resilience logic 1: State driven reassurance, resistance and bouncing back}

As noted above, in advance of the CCA, and in the wake of $9 / 11$, national government and municipal authorities were forced to confront a widespread fear that the UK, and especially its cities, would be targeted by international terrorists. This threat gave momentum to the birth of a range of national counter-terrorism and security strategies and the development of what would become specific forms of resilience policy. This prominence of such concerns led to the implementation of measures to counter such threats and increased emphasis on security couched within broadly conceived notions of resilience. These measures focused in particular on enhancing the physical robustness of the built environment and furthering 
human and technological surveillance capabilities.

This first logic of security-driven resilience was materially manifest in a number of ways. First, and with particular import for the focus of this article, electronic surveillance measures, particularly software-driven systems facilitating automated production, ordering and control of space and everyday life (Lyon, 2003), proliferated throughout public and semi-public spaces. 9/11, in particular, proved a catalytic event for the mass introduction of hi-tech surveillance systems - a surveillance surge - with the intensification and expansion of existing systems and the adoption of ever more refined tracking technologies (Ball and Webster, 2003). Second, security-driven resilience was enhanced through the increased popularity of physical or symbolic notions of the boundary and territorial enclosure, which served a defensive purpose, often through the erection of rein-forced security barriers, and of locating surveillance devices around 'at risk' sites, constructing hermetically sealed exclusion zones (Coaffee, 2004; Fussey and Coaffee, 2012). Under this logic surveillance applications adopt a range of coercive and enforcement-based roles.

This first logic of security-driven resilience has been largely state controlled and implemented

by the police and national security agencies. ${ }^{5}$ The spatiality of resilience was particularly manifest through highly surveilled and visible fortress-like security at high-risk sites such as Government buildings key financial centres and national embassies. This reaction was not unique to the UK: it characterized the initial international reaction to post-9/11 anxieties (Graham, 2004). While the need to protect key government assets within the homeland was necessarily reactive and obtrusive, such security assemblages also served a political purpose in terms of visibly demonstrating that the state was acting to protect the nation from terrorism (Boddy, 2007). Crucial here is the way in which these avowedly security-focused practices have since become articulated in terms of resilience across UK government policy, particularly notable in the latest iteration of the UK CONTEST counter-terrorism strategy (HM Government, 2011). Thus, according to this logic, over time the language of security has become recast as that of resilience without changing its fundamental focus and purpose. Such practices reflect a further enduring theme identified in critical analyses of resilience, in particular the way in which resilience planning is often translated into more narrowly conceived measures that seek robustness against potential hazards (Bosher and Dainty, 2011). Such approaches are reminiscent of Holling's (1973) critique of 'engineering resilience' orchestrated around the goal of the maintenance of stable systems which, ultimately, fail to be resilient in themselves.

Security-driven resilience logic 2: Devolving, preparing and pre-empting

While the first logic of security-driven resilience was inherently reactive and materially focused, and sought to mitigate security risk, as the 2000s proceeded increased effort was made to focus on preparedness and preventative aspects of the resilience cycle. The second logic thus moved beyond the ability to absorb shock, to focus instead on the ability of 
businesses, governments and com- munities to take preventative action. National government stakeholders increasingly sought to cooperate with regional and local authorities and a range of professional stakeholders through the development of a multi-level system of resilience governance across national, regional and local levels in the UK in line with the provisions of the CCA. In many respects such resilience practices mirror broader trends in public governance of the past 20 years, where the 'regulatory state' 'steers' via strategy and the 'rowing' of implementation is carried out locally (Osborne and Gaebler, 1993). Such drives towards multi-level action thus may be located among a number of broader processes aimed at devolving central state functions and responsibility onto the local realm, including responsibilities for emergency planning, tackling crime and disorder and, separately, terrorism. Overall, this second logic fomented a shift in the governance as well as the focus of resilience. In particular, this process enabled security concerns to become further consolidated as the central concern of resilience practice whilst national security became played out in the local realm under the aegis of resilience and community-building.

Here, actions of local governments became central in developing tailored resilience strategies against a range of risks; but most prominent among these was terrorism (Walker and Broderick, 2006), again underscoring the central role of security in more broadly conceived notions of resilience. Security-driven resilience has thus been enacted through the increasing sophistication and cost of security and contingency planning undertaken by organizations and different levels of government, intended to decrease their vulnerability and increase preparedness in the event of an attack. Most organizations have reviewed and re-evaluated their individual risk assessment approaches and local authorities have sought to become more resilient and create more effective, joined-up approaches to the governance of disaster recovery with the institutional management of any future terrorist attack given the highest priority (Coaffee, 2006; Adey and Anderson, 2012). Thus, resilience practices further coalesced around notions of security.

Notwithstanding the multi-scalar governance established to coordinate resilience practice, the ambient threat of urban terrorist attack and its realization in London on ' $7 / 7$ ' defines the second logic of security-driven resilience. ${ }^{6}$ Signifying a further collapse of distinctions between internal and external security, concerns over 'home grown terrorists' focused government attention on the so called 'Prevent' strand of national counter-terrorism policy concerned with 'the radicalization of individuals'. This became a controversial area of policy, especially with regard to the emotive language often used to describe it (for example terms such as radicals, extremists, etc.), and accusations of discrimination against particular racial or ethnic groups (Kaplan, 2006; Poynting and Mason, 2007). In a similar way to the UK, other countries have also adopted what Aly (2013) refers to as a 'softer approach' to counterterrorism - Australia's 'Resilience' approach and the US 'Diminish' being widely cited examples. In counter-distinction to the protective and state-led responses to 9/11, after $7 / 7$ there was a refocusing on localized community-based approaches towards counter-terrorism 
in the UK with ... the government acknowledging the need to work in partnership with Muslim communities to prevent young people from being radicalised in the first place and to ensure that communities were resilient enough to respond to, and challenge, extremists from within. (Briggs, 2010: 971)

The co-option of community-level groups into the provision of security-driven resilience practices has been controversial, however, amid accusations that such attempts represented a Trojan Horse for coercive state control to become intensified in local contexts (Kundnani, 2009). In the wake of $7 / 7$ the UK Government immediately set up the Preventing Extremism Together (PET) Taskforce in August 2005 to underpin this locally-focused effort and eventually this fed into enhanced funding with delivery being coordinated by local police forces and local government in conjunction with community organizations. Overall, Prevent and the series of specific policies that flowed from it - was seen as a longer-term objective where the state and its agencies attempted to tackle the root causes of extremism in a preemptive, proactive and community-focused way. ${ }^{7}$ In the UK, resilience discourses have become further implicated in combating violent extremism programmes via the language of individual resilience to radicalization (Home Office, 2011). In sum, as security has become the prominent feature of resilience practice, security assets are justified as providing resilience whilst discourses and resources of resilience are deployed to enhance security.

Mirroring the anticipatory turn in social control practices more broadly (Fussey, 2013), the prominence of this security-driven resilience logic has served to direct the use of specific surveillance and security practices towards pre-emptive and amelioratory ends. Here, for example, cam- era surveillance has been located within broader postmodern forms of penality based on the management and redistribution of risks (Norris and McCahill, 2006), rather than aspiring to modernist forms of re-normalizing or rehabilitating transgressors. In such circumstances, social control is no longer 'social'. At the same time, such practices have been accompanied by accelerated diversification in the governance of public surveillance (Fussey, 2008). Here, responsibility for providing surveillance strategies that meet local concerns, as well as protecting against state- focused transgressions such as terrorism, is devolved 'down' to lower levels of the state and non- state actors. However, the central state retains at the same time its 'trump card' status, potentially overriding local concerns, liberties and rights in areas it defines as the higher national interest. Such composite ensembles of security-driven resilience practice draw a range of competing frames and responsibilities together, generating tensions and collisions elucidated in the empirical case study below. In doing so, the delivery of security-driven resilience animates a particularly important two-part question, long established in critical security studies but only recently gaining prominence in counterpart critiques of resilience: 'what is being made resilience, and for whom?'.

Security-driven resilience logic 3: Towards local and everyday practice

Whereas the first two logics of security-driven resilience have been largely advanced by the 
state and prescribed through a range of resilience-related national strategies, over time a new logic began to emerge where there was a need for security to be balanced with other material and socio- economic considerations, and for increased responsibility to be devolved to a range of local scales and non-governmental stakeholders to achieve this end. Under this logic, businesses, governments and communities increasingly sought to anticipate shocks and, ultimately, to embed resilience in everyday activities and professional practice.

This third evolving logic of security-driven resilience also had a distinctive communitarian twist in contrast to the traditional 'command and control' approach of central government. Increasingly, however, the focus of resilience policy has been directed toward smaller spatial scales and everyday activities, which 'is premised on institutions and organisations letting go, [and] creating the necessary framework for action' (Edwards, 2009: 80, italics in original). Here, resilience is 'coming home' and practices become nested locally, providing a fit with wider UK Government ambitions to create a new, more community-driven social contract between citizens and the state. In the UK principles of resilience are now also critical with regard to the current drive towards enhanced localism (HM Government, 2010) - a policy dynamic that places emphasis on grass- roots activities and stresses the importance of anticipatory, holistic and comprehensive approaches to the changing nature of places. Thus, localized resilience approaches become realized not through state institutions, but upon localized networked responses, with governance dispersed more widely across key stakeholders and sectors. Enhanced citizen resilience is, however, still articulated through the lens of emergency planning, in the belief that greater resilience will be produced by 'communities and individuals harnessing local resources and expertise to help themselves in an emergency, in a way that complements the response of the emergency services' (Cabinet Office, 2011b: 4).

Similar to the preceding two logics, security-focused initiatives have been central to driving forward this logic of resilience. For example, in March 2010 the UK Government released a set of further guidance documents for built environment professionals concerned with enhancing built-in resilience in urban areas. These documents reinforced the message that the threat from terrorist attack was real and imminent, and that in line with the strategic framework - Working Together to Protect Crowded Places - a range of key partners including local government, the police, businesses and built environment professionals should work holistically to reduce the vulnerability of crowded places to terrorism (HM Government, 2010). This highlighted the emergence of a much more proactive, flexible, reflexive and integrated approach to resilience in urban areas. In other respects, a number of police counter-terrorism training schemes, and also public information campaigns, have placed considerable emphasis on encouraging diverse security professionals and the general public to take ownership of, and act upon, feelings of suspicion. Most visibly, untargeted highprofile publicity campaigns such as the Metropolitan Police's 'If you suspect it, report it' and Transport for London's 'It's all up to us' and 'If anything suspicious catches your eye' campaigns. More targeted and formalized measures include government-funded training of 
security professionals and other public-facing staff working in crowded places (such as shopping malls, stadia and hospitality) in a range of security aspects, including identifying and managing suspicious behaviour and materials (see Malcolm, 2013). As the discussion below illustrates, such processes agitate tensions within the politics of scale as a range of non-state stakeholders and individuals have been increasingly drawn into the delivery of security policy through a process of 'responsibilization' (Garland, 1996). Thus the governance of resilience, and particularly the interactions between citizen and state progressively place the onus for preventing and preparing for disruptive challenge onto institutions, professions, communities and individuals, rather than the state, the traditional provider of citizens' security needs (Coaffee et al., 2008). Propelled by the processes and practices generated by these three dimensions of the securitization of resilience, a far more pervasive and widespread responsibilization of citizens may be highlighted than was previously acknowledged in much security research (see, for example, Dean, 1999).

In sum, as resilience discourse and practice has proliferated over the past decade, the emergence of three distinct resilience logics can be identified. Within each is a clear gravitation towards the priorities of security and counter-terrorism, which, in turn, draw security infrastructures, organizations and practices into the delivery of resilience. With regard to the specific focus of this article, one such form of security practice, technological surveillance, is prominent within all three logics by way of its deployment to intensify the robustness of systems and infrastructure against shocks, as a tool of anticipatory control, and through its deployment across diverse localized settings. Adding further complexity to the interrelationships between security and resilience is the way security practices have become cloaked in the softer and more palatable language of resilience, thus enabling their noncoercive applications to be foregrounded. With regard to technological surveillance, for example, as the UK government CCTV strategy states, cameras must be 'fit for several purposes' (Home Office, 2007: 13) and are implicated in a range of non-coercive roles such as encouraging the use of public spaces, building a sense of safety, coordinating emergency services in an incident, and maintaining transport infrastructure flows.

\section{Project Champion: Security-driven resilience in practice}

As highlighted above, as the state's approach to security-driven resilience has evolved, so different logics have emerged which shape how resilience is put into practice across varied spatial scales. In part the ambiguity surrounding the rhetorics of security-driven resilience has proved problematic. As many have highlighted (Brand and Jax, 2007; Coaffee, 2006; Walker and Cooper, 2011) resilience is a dynamic term simultaneously applied at different scales and with different meanings. The scalar practices of resilience are thus complicated and fluid and it is therefore not surprising that as it has grown in scope and usage 'resilience' has necessarily harboured internal tensions and contradictions, as it shifted from a narrative of national protection to one of localized prevention and self-organizing responses. For example, for state actors, resilience is predominantly conceived as protection from terrorism, 
while for the community it involves grass-roots activism and collective efficacy against threats (including the state's desire to monitor them). As these diverse approaches and understandings of resilience become operationalized, their discordances become visible. It is these internal tensions that we will unpack through the following case study from Birmingham, UK.

In June 2010 the media reported on a security project to install 290 surveillance cameras in Birmingham. Given the normalization of surveillance practices within the UK, at first glance many aspects of this initiative were not particularly novel. What was exceptional about the adoption of such practices in this instance, however, was the scale, technological sophistication and location of the operation. Of the high-specification surveillance cameras in 'Project Champion', 150 came equipped with Automated Number Plate Recognition (ANPR) capability, developed from former military technology that could automatically monitor all vehicles entering and exiting the areas; whilst a further 72 covert cameras were camouflaged within street signs, furniture and other features of the urban landscape. Most controversially, the cameras encircled two predominantly Muslim neighbourhoods of the city, thus articulating elements of the first security-driven logic of resilience outlined above: the use of borders, perimeters and architectures of surveillance. Here, however - with encirclement achieved through technological rather than physical perimeters, and the replacement of defended and valuable intramural spaces with those of containment and crude categorical suspicion - a number of variations on the theme can be observed. The subsequent media storm and local community outcry served to exemplify the tension existing in various security-driven logics of resilience with regard to core ideas of protection, prevention, anticipation and localism. In addition, the impact and fallout from Project Champion illustrates the convergence of the three logics of security-driven resilience and how their simultaneous pursuit generates inevitable conflicts and collisions, with one particular fault line converging on the divisive nature of the scheme and attempts by the local state to engage the community in security and crime reduction initiatives. The rise and fall of the project also served to illuminate tensions associated with security-driven resilience; civil liberties and the limits of public acceptability; the material visibility of security infrastructure; the modulation of different scales of resilience and how a range of different actors become involved in resilience governance; and, the labelling of 'dangerous' (and disadvantaged) populations through anticipatory means.

This section draws on empirical research conducted with security and policing professionals since 2009. Sustained relationships with key gatekeepers enabled access to a number of formerly closed research environments including counter-terrorism training schemes, briefings, practitioner conferences and community engagement programmes. Documents were both provided by Birmingham City Council and sourced from police and local authority reviews of the scheme. Funding plans were obtained using Freedom of Information requests. Interviews were conducted with representatives from central government and a range of policing agencies. These included participants from the West Midlands Police Authority 
(WMPA), the regional policing body that drove the implementation of the scheme; the Safer Birmingham Partnership (SBP), the local municipal organization responsible for community safety in the area; local CCTV managers; and the National Police Improvement Agency (then responsible for developing and delivering the national CCTV Strategy for England and Wales (Home Office, 2007)).

In the UK, counter-terrorism operations have largely concentrated on a small number of high- density urban areas. As a corollary, entire security architectures became installed in highly specified areas, the focus spilling over from intended subjects and resting categorically on associates, networks and geographies. Geographical suspicion was a key driver for the inception and intended installation of Project Champion. The scheme was originally conceived after the (narrowly) failed London nightclub and Glasgow airport bombings of 2007, with the siting of cameras determined by the location of several prior high profile terrorist plots originating from specific parts of Birmingham (verbal interview with police officer with responsibilities for CT in the region, unpublished). These included the first attempted UK-based al Qaeda plot (during 2000), the arrest of a suspected Taliban 'commander' and, perhaps most famously, 'Operation Gamble', a plot to kidnap and dismember Muslim soldiers serving in the British Army, resulting in five convictions and leading law enforcement professionals to apply ecological perceptions of dangerousness to specific parts of the city (verbal interview with police officer with responsibilities for CT in the region, unpublished). These perceptions converged on Sparkbrook and Washwood Heath, two residential areas with high Muslim populations and home to 11 people convicted for terrorist-related activity between 2007 and 2011. These became the neighbourhoods encircled by the 290 Project Champion cameras.

Sparkbrook and Washwood heath are inner-city neighbourhoods with similar population sizes of just over 30,000 people each. Other shared characteristics include high levels of ethnic diversity, and of unemployment and other socio-economic disadvantage. For example, no more than $10.4 \%$ of the population of either Sparkbrook or Washwood Heath are classed as white British, in contrast to the significantly higher levels in England (79.8\%) and Birmingham (52.1\%) (Birmingham City Council, 2011; Office of National Statistics, 2011). Moreover, both neighbourhoods have large concentrations of 'suspect populations' subjected to other forms of law enforcement attention (Kundnani, 2009). Forty-two per cent of Sparkbrook's population identifies itself as Asian/Asian British Pakistani, with 10\% self-identifying as 'Arab', with significant numbers of Somalis also residing there (Office of National Statistics, 2011). Washwood Heath's population has a higher Asian/Asian British Pakistani population (57\%) with significant numbers (5\%) of residents identifying themselves as Bangladeshi and Kashmiri (as distinct from either Indian or Pakistani) (Office of National Statistics, 2011). Also notable are the high levels of socio-economic disadvantage, with more than $40 \%$ of households having no adults in employment in each area (Office of National Statistics, 2011). Beyond describing the demographic com- position of each area, such statistics have important consequences for the way official agencies seek to engage with residents, how 
variants of security-driven resilience are applied, and how they are received, responded to and resisted by communities.

In particular, such groups harbour classic characteristics of what UK local authorities have (potentially perniciously) called 'hard-to-reach groups'. Amongst others, these two neighbourhoods, also provided the sites for a range of investments targeted at regeneration and 'community- building', including the engagement of residents in expressing and setting priorities for crime reduction (interview with local authority communities manager, 2010), activities analogous with the development of 'community resilience' outlined above. Thus, in this setting the third logic of security-driven resilience engages the same communities that are targeted by the first.

In March 2008 WMP received $£ 3$ million funding to deploy over 200 cameras, many of which were ANPR enabled (ACPO [TAM], 2007). Birmingham City Council also agreed to invest $£ 500,000$ to assist WMP with running the scheme (Isakjee and Allen, 2013: 7). Such a 'ring of steel' vehicle monitoring approach is by no means unique to the UK, having been used in the financial zones of the City of London since the early 1990s (Coaffee, 2003), but the importation of such strategies into a residential area and the enactment of categorical suspicion on such as scale was novel.

From its inception, Project Champion was intended to institute both obtrusive and unobtrusive monitoring regimes in which 'suspicious' subjects were tracked and monitored 'from a distance', ensuring the safety of police officers and allowing recordings to take place unhindered (Fussey, 2013). Such ambitions to 'police from afar' contrast with the public participatory and community engagement remits of Birmingham's municipal crime reduction body (the SBP, also responsible for managing the city's surveillance cameras on a day-to-day basis), and thus illustrate tensions between different agencies, using the same technologies but with different aims and protocols and thus occupying different positions in the governance of social control. In doing so, it reveals inherent antagonisms between the different logics of security-driven resilience as they are applied in practice. Here, particular tensions exist between the first and the third logics whereby national security agendas become nested within, and abrade with, local community safety concerns and practices.

Related to this, Project Champion also revealed fundamental questions regarding visibility and transparency in processes of security-driven resilience. We need here to gain a greater appreciation of the impact of both visible and invisible security measures: how such apparatuses 'transmit' symbolic messages, as well as the variety of ways in which security might be 'received' by its subjects. As Andersen and Möller (2013: 203) emphasize, this knowledge 'facilitates understanding of the extent to which current societies are penetrated by the ideas and practices of security and surveillance, and furthers investigation of the discursive structures that enable such penetration'. The Project Champion scheme, both materially and in terms of transparent governance, highlights the opacity of many security- 
driven resilience initiatives. The active concealment of hi-tech cameras, although never activated, symbolically (at least in the eyes of local communities) represented an attempt to introduce espionage-style techniques into the neighbourhood. A key issue here is that whilst the placement and function of overt security measures can be actively contested, those that are more unobtrusive tend to be implemented without reproach. Thus, while 'invisible' security may be beneficial from a security and surveillance perspective it also brings a range of challenges regarding who makes decisions and how decision makers and processes are monitored. In other words, as Coaffee et al. (2009: 506) noted, 'invisible forms of security may risk becoming an uncontested element of political and public policy'. Moreover, as shown in Project Champion, the concealment of the purpose of security-driven resilience can have major implications for trust between citizens and police at a time when community resilience is expanding in scope and importance within national security policy with these two groups mutually reliant on each other for the delivery of security and resilience.

From the perspective of Birmingham City Council, Project Champion later became viewed negatively as it emerged that counter-terrorism concerns were 'hitch-hiking' on the community safety agenda in order to seek justification and legitimation for more controversial proposals. For example, it was reported that the SBP, asserted that, at the first meeting between the police and the SBP/local authority, the police never advised that the scheme was a counter-terrorism operation (Birmingham City Council, 2010: 28). Members of the WMPA present at the same meeting claimed the opposite: that there had been 'no confusion that the principle and exclusive objectives of the Project were driven by the counter-terrorism risk' (Birmingham City Council, 2010). There is evidence to suggest that the police certainly made judicious use of the 'crime' issue, as part of a broader 'drip feed' of information from the police to the local authority (senior SBP member, unpublished interview October, 2010) and thus viewed their relationship with SBP in instrumental terms. Several other factors support this version of events, highlighting how WMPA effectively rationalized Project Champion post hoc as a solution to high crime areas as a more expedient, politically acceptable and legitimate guise to introduce a more controversial strategy (Thames Valley Police, 2010: 16) rather than the inherently negative and politically unacceptable labelling of geographical areas as 'hotbeds' of radicalization. Critical tensions thus emerge between the first and second logics of security-driven resilience. Central and local state responses clash through this instrumental use of local state community safety architectures which were used to deploy highly focused coercive counter-terrorism initiatives, ultimately undermining the legitimacy of the former (see Birmingham City Council, 2010).

Thus the population of particular territories, with a diversity of actors and coalitions and with different logics of security-driven resilience, does not necessarily translate into a coherent approach on the ground given the very different uses made of high-tech surveillance for anticrime and counter-terrorism purposes. In this sense, heterogeneous elements remain diverse and diverse logics abrade even when drawn into tentative coalition. 
Project Champion was also detached from other community-focused policing and local authority approaches to security-driven resilience being undertaken in the area. In particular, WMP had established a dedicated department within its Counter Terrorism Unit (CTU) to focus on developing successful partnerships with a range of local civil society organizations and institutions in order to drive forward the Prevent agenda. For example, dedicated 'Security and Partnerships Officers' were working across key neighbourhoods - in schools, mosques, community centres, and sports clubs - to encourage community-wide action to defeat violent extremism. However, this has proved to be a problematic relationship to maintain, with a subsequent Institute of Race Relations report (Kundnani, 2009) noting that a parliamentary committee meeting (House of Commons, 2010) regarded the 'embedding' of counter-terrorism police in local services as a major cause for concern for Muslim communities.

The events relating to this initial phase of Project Champion highlight a series of fissures amongst the approaches used in the delivery of a nationally important but locally focused security- driven resilience initiative, placing community approaches at odds with protective logics of security in a way that effectively stigmatized the area (Isakjee and Allen, 2013). Eventually this led, in response to a media outcry which, in the words of Beck (1995: 100), 'sounded the social alarm', to significant resistance to the scheme from local residents amidst complaints that the intentions and sheer scale of the surveillance deployment had been masked. However, despite media representations pitching a Manichean conflict between those applying and those subjected to Project Champion's cameras, initial resistance to the scheme emerged from those less directly targeted by their gaze. ${ }^{8}$

Initial protests began in the more affluent neighbouring district of Moseley, where residents queried the installation of camera stanchions in their streets, feeling it diminished the aesthetic appeal of the area. Despite their status as public backers and legitimators of the scheme, representatives of the municipal Safer Birmingham Partnership attending a meeting of these residents had no knowledge of the location or extent to which counter-terrorism police had introduced the scheme (Safer Birmingham Partnership representative, interviewed March 2011, unpublished). In addition to being criticized by the public for the scheme, and excluded by the police from any prospect of using the promised integrated system for municipal ends, the origins of this disquiet signify a further difficulty. Here, it was affluent suburban social movements that managed to mobilize their grievances. Moreover, in addition to highlighting fractures between the local and central state, such events illustrate the limited extent of engagement with local communities under the third logic of securitydriven resilience.

Local communities were outraged when Project Champion became public knowledge and, through community leaders, organized a series of public meeting to protest about the 
initiative as well as to seek clarity as to where the covert cameras were actually sited. With the backdrop of large public meetings, tensions escalated and by June 2010 news of Project Champion reached the national media. As one local protestor noted:

Now the truth is out, there's a lot of anger. Certain communities have been ring-fenced and saturated with cameras, making it impossible for you to get in or out without being tracked. What's happening here is the government is spying on its citizens covertly in some cases, without their knowledge or consent, and it's a gross invasion of privacy and civil liberties. (BBC, 2010a)

Surveillance had thus become a visible symbol of a pernicious expression of security-driven resilience. A formal public consultation was forced, which led to 'hoods' being placed over the visible ANPR cameras in July 2010 pending 'further consultation', although, as the BBC (2010b) noted at the time, the cameras were not being disabled and the hidden cameras were, in theory, still useable.

The subsequent independent investigation and report by Thames Valley Police was highly critical of both the Project Champion scheme and WMP which, it claimed, had done irreparable harm to community-police relations. In the wake of this report the camera network was dismantled in mid-2011, during which time the police stated that the cameras had never actually been activated. Birmingham City Council also carried out its own review into the handling of Project Champion and concluded that the cameras should be removed. The legacy of the local Project Champion scheme was, however, destined to have national importance, with the hardware that was installed being redeployed in London and other areas of the UK in the policing of the 2012 Olympic and Paralympic Games (BBC, 2011). Fiftythree of the cameras were eventually sold to other forces (for $f 1$ each) to help with the wider Olympic security operations (Birmingham Mail, 2012). With the Games hosted in an urban area accommodating Western Europe's most populous Muslim com- munities, former objections to the cameras were seemingly swept aside in face of the ephemeral and exceptional security demands of these major international sporting events (Fussey et al., 2011). Another postscript to the Project Champion story reveals further the longevity of conflict and tensions accompanying the scheme. In the wake of convictions of a number of Sparkbrook residents for a failed suicide bomb plot in early 2013 which, if successful, would have killed more people than the $7 / 7$ attacks in London, local parliamentarian Khalid Mahmood argued that the relaunch of Project Champion 'could ensure the safety and security for people in Birmingham and the whole UK ... [the cameras] would have been a huge asset and it has been lost. I now want to see a replacement' (Birmingham Mail, 2013). Thus, once competing narratives and logics of security-driven resilience are brought together they may be outlasted by the conflict they generate.

\section{Conclusions: Resilience and tensions of devolved state security logics}


This article has traced the relationship between security and resilience policy, and practice in its development has led to the dominance of security concerns and the emergence of three distinct security-driven logics of resilience. The prominence of anticipatory and preventative approaches within these logics has served to draw security architectures - particularly those emphasizing modes of surveillance, observation and knowledge-gathering - into the practice of resilience. At the same time, the co-purposing of surveillance and other social control strategies towards both security and broader, more seemingly benign resilience practices enables their deployment under more palatable auspices. Through an analysis of the operationalization of these security-driven resilience logics with regard to one specific security scheme, Project Champion in Birmingham, the article has revealed a number of tensions within and between these logics that become animated as these practices become implemented. These include the remapping of scale on security; the shift in focus from protection towards local self-organization; the anticipatory turn in both crime control and national security; and the increasing array of security 'actors' who now have a responsibility for national security and counter-terrorism operations.

Illuminated through the empirical study of Project Champion, the principal argument is that the modulations between different logics and scales of security-driven resilience exist in perpetual tension and thus do not necessarily translate into any coherent form of social control on the ground. Ultimately, such discordances reveal inherent antagonisms within resilience strategies that are reliant on coproduction and codelivery between the controller and those controlled. However, the importance of these frictions goes beyond incoherencies and tensions within broader assemblages of action, to reveal a range of processes concerning the governance and scaling of security-driven resilience practice. These are discussed in turn, as follows.

Underpinned by the rise of resilience as the discourse of choice for new national security imperatives, this article has highlighted multiple and heterogeneous processes that lie behind policy rhetoric and which become spatially imprinted in local areas. The broader mainstreaming drivers of security-driven resilience practice and logic further agitate such tensions and frictions. As this article has argued, such drivers include the shifting governance of resilience practice and the de- institutionalizing of security.

Separately, analysis of Project Champion also reveals a number of insights concerning the 'responsibilizing' (Garland, 1996) of ever-increasing numbers of local, public-facing individuals and agencies into (security-driven) resilience roles. As Chandler (2012: 216) noted, the discourse of resilience has facilitated 'a shift' in dominant security discourse in terms of scale of intervention. Its policies encourage the development of community or institutional resilience and of the 'responsible citizen' in accordance with new techniques of governmentality: the replacement of state-centric 'protective' security approaches with those emphasizing 'self-organizing' human security. As recent work on resilient subjectivity in late modernity has also argued, resilience pol- icy appears to be part of 'a complex of 
scientifically grounded techniques of the self, necessary to optimize autonomous subject in an age of high uncertainty' (O'Malley, 2010: 488). Such 'optimization' projects targeted at socalled 'neurotic citizens' (Isin, 2004) are now widespread and seek to shift responsibility to general local level governing practices and non-government subjects.

However, for all the focus on local and subjective individual performance of resilience functions (and their absorption of resilience failures), the persistence of state governance from a distance (Fussey, 2004; Joseph, 2013) enables multiple extant hierarchies and separations of tasks to remain and exert themselves. At the same time, the proliferation of resilience discourse has led to increasingly broad coalitions of practice and a cluttered organizational landscape. Moreover, new networks of practice have long been understood to generate new hierarchical arrangements (see, for example, Latour, 1988), a process also evident in this analysis of assembled coalitions of security-driven resilience and the primacy afforded to specific readings of security within these arrangements.

In one sense it is worth recognizing not only the existence and inevitability of such scalings, but also their material and political consequences. Adey and Anderson (2011), for example, recognize how within emergency response activities such scaling may enable efficiency and accountability. However, the opacity of many security-driven resilience initiatives, the politicized nature of hierarchical relationships within resilience practice, and the specific politics that such arrangements produce mean such aspirations are not always easy to realize.

In many ways, security-driven resilience, and its execution through surveillance practices, is increasingly normalized within modern society and has become a key mode of organizing contemporary neoliberal society. Logics of protection, reassurance, adaptation, preparedness and prevention can be identified; pre-managed risk, control and security, increasingly feeding into an ever-increasing range of national and local policy and practice. Resilience, emerging predominantly as a security-focused policy connected to countering the threat of international terrorism, is now fully embedded as a policy metaphor for envisioning future local place-making and community building activities alongside broader scale national security concerns.

As we have highlighted, domestic security environments - generated and sustained though the lens of resilience - are heavily mediated by complex and often contradictory practices. In Birmingham, the resilience logics of territorial enclosure, where high-risk sites are fortified against exogenous threats, underwent a transposition towards the enclosure of endogenous 'risks' within technological perimeters. These divisions are abundant and serve to underline the fragmented nature of security-driven resilience. As these develop, these contested outcomes, together with the security-focused practices that stimulate them, increasingly resemble the antithesis of long-understood principles and conditions of what makes something resilient. These include the accent on themes such as connectivity, coherency, 
adaptation and flexibility that have been at the heart of discussions on resilience, and of what makes something resilient, over the last 40 years (see, for example, Holling, 1973). In doing so, the realization of complex, convoluted and contradictory security-driven resilience practices may mutate into practices that ultimately subvert some of the founding principles of resilience logic itself.

\section{Notes}

1. This Act came into force in November 2005. See also see UK Resilience website within the Cabinet Office (http://www.cabinetoffice.gov.uk/ukresilience) which pre-dated the CCA. The CCA aimed to establish 'a modern framework for civil protection capable of meeting the challenges of the 21st century' (Security Service, 2006).

2. This strategy was developed from 2003 but only made public in 2006. Updated versions were released in 2009 and 2011.

3. See also a revised version published in 2010 (Cabinet Office, 2010).

4. See also updated 2011 version.

5. In the UK this involves, for example, the Centre for the Protection of National Infrastructure (CPNI), the National Counter-Terrorism Security Office (NaCTSO) and the Civil Contingencies Secretariat.

6. In a series of coordinated attacks on London's transport network on 7 July 2005, suicide bombers killed 52 and injured 770 people.

7. Similarly, in the USA, Canada and Australia, for example, a core approach of localized counter vio- lent extremism (CVE) strategies has been the attempted development of 'community resilience' more generally

8. Resistance to Project Champion has been covered in greater detail elsewhere (see, for example, Fussey, 2013) and it is beyond the scope of this paper to provide a detailed exegesis of its development. Key points are relayed here to illustrate the tensions between scalings and logics of security-driven resilience practice. 


\section{References}

ACPO (TAM) (Association of Chief Police Officers (Terrorism and Allied Matters) (2007) Strategic Outline Business Case - ACPO TAM Business Area. Available at: http://www.whatdotheyknow.com/ (accessed 1 December 2007).

Adey P and Anderson B (2011) Affect and security: Exercising emergency in 'UK civil contingencies'. Environment and Planning D: Society and Space 29(6): 1092-1109.

Adey P and Anderson B (2012) Anticipating emergencies: Technologies of preparedness and the matter of security. Security Dialogue 43(2): 99-117.

Aly A (2013) The policy response to home-grown terrorism: Reconceptualising Prevent and Resilience as collective resistance. Journal of Policing, Intelligence and Counter Terrorism 8(1): 2-18. Amin A (2013) Surviving the turbulent future. Environment and Planning: D 31(1): 140-156.

Andersen R and Möller F (2013) Engaging the limits of visibility: Photography, security and surveillance. Security Dialogue 44(3): 203-221.

Ball K and Webster F (eds) (2003) The Intensification of Surveillance: Crime, Terrorism and Warfare in the Information Age. London: Pluto Press.

Bauman Z, Bigo D, Esteves P, Guild E, Jabri V, Lyon D and Walker R (2014) After Snowden: Rethinking the impact of surveillance. International Political Sociology 8(2): 121-144.

BBC (2010a) Plastic bags to be put over Birmingham 'terror cameras'. 17 June. Available at: http://www.bbc. co.uk/news/10337961 (accessed 17 June 2010).

BBC (2010b) CCTV cameras in Birmingham are covered with hoods. 1 July. Available at: http://www.bbc. co.uk/news/10477801 (accessed 1 July 2010).

BBC (2011) Birmingham Project Champion 'spy' cameras being removed. 9 May. Available at: http://www. bbc.co.uk/news/uk-england-birmingham-13331161 (accessed 9 May 2011).

BBC (2013) EDL Birmingham protest: Bottles thrown at police. 20 July 20. http://www.bbc.co.uk/news/uk- england-birmingham-23390232 (accessed 20 July 2013).

Beck U (1995) Ecological Politics in an Age of Risk. Cambridge: Polity Press. Birmingham City Council (2010) Project Champion: Scrutiny Review into ANPR and CCTV Cameras,

Birmingham: Birmingham City Council. Birmingham City Council (2011) Population and Census Data. Available at: http://www.birmingham.gov.uk/cs/Satellite?c=Page\&childpagename=Planning-andRegeneration\%2FPageLayout\&cid=122309635 
3755\&pagename=BCC\%2FCommon\%2FWrapper\%2FWrapper (accessed 14 August 2014).

Birmingham Mail (2012) 64 'spy' cameras used for doomed Project Champion to be destroyed costing E300k. 2 November. Available at: http://www.birminghammail.co.uk/news/local-news/birminghams-project- champion-antiterror-cctv-280264 (accessed 2 November 2012).

Birmingham Mail (2013) Bring back the Project Champion spy cameras in Birmingham, says city's Muslim MP. 23 February. Available at: http://www.birminghammail.co.uk/news/localnews/bring-back-project- champion-spy-1343736 (accessed 23 February 2013).

Boddy T (2007) Architecture emblematic: Hardened sites and softened symbols. In: Sorkin M (ed.) Indefensible Space. Abingdon: Routledge, pp. 277-304.

Booth K (2004) Realities of security. International Relations 18(1): 4-5.

Bosher L and Dainty A (2011) Disaster risk reduction and 'built-in' resilience: Towards overarching principles for construction practice. Disasters 35(1): 1-18.

Brand $\mathrm{F}$ and Jax K (2007) Focusing the meaning(s) of resilience: Resilience as a descriptive concept and a boundary object. Ecology and Society 12(1): 23.

Brenner N (2000) The urban question: Reflections on Henri Lefebvre, urban theory and the politics of scale. International Journal of Urban and Regional Research 24(2): 361-378.

Briggs R (2010) Community engagement for counter-terrorism: Lessons from the United Kingdom. International Affairs 86(4): 971-981.

Burby R, Deyle R, Godschalk D and Olhanksky R (2000) Creating hazard resilient communities through land-use planning. Natural Hazards Review 1(2): 99-106.

Cabinet Office (2005) Dealing with Disaster, 3rd edn. London: Cabinet Office.

Cabinet Office (2008) The National Security Strategy of the United Kingdom Security in an Interdependent World. London: HMSO.

Cabinet Office (2010) A Strong Britain in an Age of Uncertainty: The National Security Strategy. London:

Cabinet Office. Cabinet Office (2011a) Big Society. Available at: http://www.cabinetoffice.gov.uk/big-society (accessed 1

December 2011). Cabinet Office (2011b) Keeping the Country Running: Natural Hazards and Infrastructure.

Available

at: 
http://www.cabinetoffice.gov.uk/sites/default/files/resources/natural-hazardsinfrastructure.pdf (accessed 1 December 2011)

Chandler D (2012) Resilience and human security: The post-interventionist paradigm. Security Dialogue 43(3): 213-229.

Chandler D (2014) Resilience: The Governance of Complexity. London: Routledge.

Coaffee J (2003) Terrorism, Risk and the City. Aldershot: Ashgate.

Coaffee J (2004) Rings of steel, rings of concrete and rings of confidence: Designing out terrorism in central London pre- and post-9/11. International Journal of Urban and Regional Research 28(1): 201-211.

Coaffee J (2006) From counter-terrorism to resilience. European Legacy: Journal of the International Society for the Study of European Ideas 11(4): 389-403.

Coaffee J (2009) Terrorism, Risk and the Global City - towards urban resilience. Farnham: Ashgate.

Coaffee J (2010) Protecting vulnerable cities: The UK resilience response to defending everyday urban infrastructure. International Affairs 86(4): 939-954.

Coaffee J (2013) Rescaling and responsibilising the politics of urban resilience: From national security to local place-making. Politics 33(4): 240-252.

Coaffee J and Murakami-Wood D (2006) Security is coming home: Rethinking scale and constructing resilience in the global urban response to terrorist risk. International Relations 20(4): 503-517.

Coaffee J, Murakami-Wood D and Rogers P (2008) The Everyday Resilience of the City: How Cities Respond to Terrorism and Disaster. Basingstoke: Palgrave-Macmillan.

Coaffee J, O'Hare P and Hawkesworth M (2009) The visibility of (in)security: The aesthetics of planning urban defences against terrorism. Security Dialogue 40(4-5): 489-511.

Dainty ARJ and Bosher LS (2008) Integrating resilience into construction practice. In: Bosher LS (ed.) Hazards and the Built Environment: Attaining Built-in Resilience. London: Taylor and Francis.

Dean M (1999) Governmentality: Power and Rule in Modern Society, Thousand Oaks, CA: SAGE.

Edwards C (2009) Resilient Nation. London: Demos. 
Fraser A (2010) The craft of scalar practices. Environment and Planning: A 42(2): 332-346.

Fussey P (2004) New Labour and new surveillance: Theoretical and political ramifications of CCTV implementation in the UK. Surveillance and Society 2(2/3): 251-269.

Fussey P (2008) Beyond Liberty, Beyond Security: The Politics of Public Surveillance. British Politics 3(1): 120-135.

Fussey P (2013) Contested topologies of UK counter-terrorist surveillance: The rise and fall of Project Champion. Critical Studies on Terrorism 6(3): 351-370.

Fussey P and Coaffee J (2012) Urban spaces of surveillance. In: Lyon D, Haggerty K and Ball K (eds) Routledge International Handbook of Surveillance Studies. London: Routledge.

Fussey P, Coaffee J, Armstrong G and Hobbs D (2011) Securing and Sustaining the Olympic City: Reconfiguring London for 2012 and beyond. Aldershot: Ashgate.

Garland D (1996) The limits of the sovereign state: Strategies of crime control in contemporary society. British Journal of Criminology 36(4): 445-471.

Graham S (2004) Cities, War and Terrorism: Towards an Urban Geopolitics. Oxford: Blackwell.

Greenwald G (2014) No Place to Hide: Edward Snowden, the NSA and the Surveillance State. London: Hamish Hamilton.

HM Government (2006) Countering International Terrorism: The United Kingdom's Strategy. CM6888. London: Stationery Office.

HM Government (2008) Preventing Violent Extremism: A Strategy for Delivery. London: The Stationery Office.

HM Government (2010) Working Together to Protect Crowded Places. London: The Stationery Office.

HM Government (2011) Contest Strategy. London, UK: The Stationary Office.

Holling CS (1973) Resilience and stability of ecological systems. Annual Review of Ecology and Systematics 4: 1-23.

Holling CS (2001) Understanding the complexity of economic, ecological, and social systems. Ecosystems 4(5): 390-405.

Home Office (2007) National CCTV Strategy. London: HMSO.

Home Office (2011) Understanding Vulnerability and Resilience in Individuals to the Influence of Al Qa'ida Violent Extremism. London: HMSO. 
House of Commons (2010) Communities and Local Government Committee: Preventing Violent Extremism, Sixth Report of Session 2009-10. Report, with formal minutes, oral and written evidence, 6 March. London: HMSO.

Isakjee A and Allen C (2013) 'A catastrophic lack of inquisitiveness': A critical study of the impact and narrative of the Project Champion surveillance project in Birmingham. Ethnicities 13(6): 751-770.

Isin EF (2004) The neurotic citizen. Citizenship Studies 8(3): 217-235.

Joseph J (2013) Resilience in UK and French security strategy: An Anglo-Saxon bias? Politics 33(4): 253-264

Kaplan J (2006) Islamaphobia in America? September 11 and Islamophobic hate crime. Terrorism and Political Violence 18(1): 1-33.

Kundnani, A (2009) Spooked: How not to prevent violent extremism, London: Institute of Race Relations.

Latour B (1988) Science in Action: How to Follow Scientists and Engineers Through Society. Cambridge, MA: Harvard University Press.

Luthar SS, Cicchetti D and Becker B (2000) The construct of resilience: A critical evaluation and guidelines for future work. Child Development 71(3): 543-562.

Lyon D (2003) Surveillance as social sorting: Computer codes and mobile bodies. In: Lyon D (ed.) Surveillance as Social Sorting: Privacy, Risk and Digital Discrimination. London: Routledge.

Lyon D (1994) The Electronic Eye: The rise of surveillance society. Cambridge: Polity Press.

Malcolm J (2013) Project Argus and the resilient citizen. Politics 33(4): 311-321.

Masten AS (2001) Ordinary magic: Resilience processes in development. American Psychologist 56(3): 227-238.

Neocleous M (2013) Resisting resilience. Radical Philosophy 178: 2-7.

Norris C and McCahill M (2006) CCTV: Beyond penal modernism? British Journal of Criminology 46(1): 97-118.

Office of National Statistics (2011) UK Census Data 2011. Available at: http://www.ukcensusdata.com (accessed 14 August 2014).

O'Malley P (2010) Resilient subjects: Uncertainty, warfare and liberalism. Economy and 
Society 39(4): 488- 509.

Osborne D and Gaebler T (1993) Reinventing Government: How the Entrepreneurial Spirit is Transforming the Public Sector. New York: Plume Publications.

Poynting S and Mason V (2007) The resistible rise of Islamophobia: Anti-Muslim racism in the UK and Australia before 11 September 2001. Journal of Sociology 43(1): 61-86.

Raco M and Street E (2012) Resilience planning, economic change and the politics of postrecession develop- ment in London and Hong Kong. Urban Studies 49(5): 1065-1087.

Security Services (MI5) (2006) Protecting Against Terrorism. London: The Stationary Office.

Thames Valley Police (2010) Project Champion Review. London: Thames Valley Police.

UNISDR (United Nations International Strategy for Disaster Reduction) (2012) How to Make Cities More Resilient: A Handbook for Local Government. Geneva, Switzerland: UNISDR.

Walker C and Broderick J (2006) The Civil Contingencies Act 2004: Risk Resilience, and the Law in the United Kingdom Oxford: Oxford University Press.

Walker J and Cooper M (2011) Genealogies of resilience: From systems ecology to the political economy of crisis adaptation. Security Dialogue 42(2): 143-160.

Zolli A and Healy A (2012) Resilience: Why Things Bounce Back. London: Headline. 